\title{
Embedding Professional Issues within University Degree Courses
}

\author{
Les Neal (and alii) \\ British computer society \\ les.neal@which.net
}

\begin{abstract}
This paper will address the British Computer Society's (BCS) requirements for accreditation with respect to the content and delivery of professional issues within UK Information Systems and Computing undergraduate degree courses. We shall discuss the professionalism required of BCS members in general, the requirements placed on computing degree programmes by the UK academic authorities and then the specific requirements placed on such courses for them to meet BCS accreditation demands. The major issues that need to be addressed positively by the providers of the programmes will be presented and we will conclude by relating the success of the enterprise to its implementation through the application of self-regulatory and democratic principles.
\end{abstract}

Keywords: Accreditation, Professionalism, Ethical issues, UK degree courses

\section{Introduction}

The departments of nearly all UK universities running undergraduate degree courses in information systems and computing voluntarily offer those courses for accreditation by the UK professional body, the British Computer Society (BCS). All such courses are also expected to conform to the national benchmark of the Qualification Assurance Agency (QAA). This is a body set up by the Universities charged with overseeing the quality and standards of all UK degree courses, not just those in the computing area. While there is a close synergy between the two bodies, the requirements do differ with the BCS placing greater emphasis on the preparation of future computer professionals, particularly in their knowledge of the real world and their professional behaviour within it. 
Having such bodies impose requirements on the content and context of such courses, might, at first sight, imply the need for strict control regimes. As this paper explains, this is not the case as historically good relationships have grown up between those carrying out the reviews and those at the receiving end. The reason for this good relationship is that inspections are based on democratic principles that imply a great degree of self-regulation, as opposed to a heavy-handed approach of inspection imposed from outside.

\section{The British Computer Society}

The British Computer Society (ref. 1), under its Royal Charter, is required to establish and maintain standards of professional competence, conduct and ethical practice for information systems practitioners. This duty includes the responsibility to develop and maintain standards for the educational foundation appropriate to people wishing to follow a career in information systems. Although fifty years old, the Society is a 'new' engineering institution compared with many that received charters in the late $19^{\text {th }}$ and early $20^{\text {th }}$ centuries. As such there is a strong UK tradition in the acceptance of chartered bodies as leading the professions and setting out the standards and behaviour expected of their members. Suffice to say, the BCS takes professionalism as central to its role in maintaining the standards of the profession and actively promotes this area within the education of prospective entrants to the profession.

To this end all BCS members have to conform to the Society's Code of Conduct (ref. 2). This covers the three areas of The Public Interest, Duty to the Profession, and Professional Competence and Integrity. The Society's Qualifications and Standards Board is charged with maintaining the Code through the offices of an Ethics Expert Panel made of up of senior members of the Society.

The following is a part of the Code of Conduct that is relevant to the focus of this paper.

In your professional role you shall have regard for the public health, safety and the environment.You shall ensure that within your professional field/s you have knowledge and understanding of relevant legislation, regulations and standards, and that you comply with such requirements. You shall conduct your professional activities without discrimination against clients or colleagues

\section{Qualification Assurance Agency}

\subsection{Background}

Historically within the UK University system there has been a great degree of independence from government, particularly by those well-established institutions that have not been heavily dependant on government money. However, with the university expansions of the late 1960s and again of the 1990s, many more universities have become increasingly reliant on government funding. Consequently it is a legitimate question for the funders to ask how well the money is being spent, with accountability being more and more central to government thinking. 
In the 1970 s, to ensure the quality and standards of the then new universities a Council of National Academic Awards (CNAA) was created with over a hundred institutions seeking approval for their degree courses. This applied to the exPolytechnics, but not to the previously established city and redbrick universities. Subject panels for each discipline were set up and any new degree had to receive CNAA approval.

The 1990s saw increasing pressure for accountability to Government paymasters. The universities as a whole were able to resist direct government intervention by setting up the Quality Assurance Agency (QAA) for Higher Education (ref. 3) in 1997. This is an independent body funded by subscriptions from all UK universities and works through contracts with the main UK higher education funding bodies. The mission of the QAA is to safeguard the public interest in maintaining standards of higher education qualifications and to inform and encourage continuous improvement in the management of the quality of higher education. This is done by working with higher education institutions to define academic standards, and by carrying out and publishing reviews against these standards.

\subsection{Subject Benchmarks}

Working closely with the sector, the QAA have published subject benchmark statements (ref. 5) designed to make explicit the general academic characteristics and standards of degree programmes in the UK. Subject benchmark statements set out expectations about standards of degrees in a range of 46 subject areas. They describe what gives a discipline its coherence and identity, and define what can be expected of a graduate in terms of the techniques and skills needed to develop understanding in the subject. Subject benchmark statements represent general expectations about the standards for the award of qualifications at a given level and articulate the attributes and capabilities that those possessing such qualifications should be able to demonstrate.

All recognised degree courses in Information Systems and Computing are expected to conform to the QAA Computing Benchmark. Indeed it is an initial condition that any course seeking BCS accreditation does so - see the next Section. This paper is concerned with one aspect of the Computing benchmark, namely the requirements for the professional, moral and ethical issues that are expected to be covered within any recognised computing degree.

The benchmark is set out in terms of abilities and standards. The following is the part of the abilities section that is directly relevant to the focus of this paper.

\section{Computing-related cognitive abilities}

Students should recognise the professional, moral and ethical issues involved in the exploitation of computer technology and be guided by the adoption of appropriate professional, ethical and legal practices.

Benchmarking standards are defined at threshold and modal levels. The threshold standard is interpreted to mean that all students (taken over all years) graduating with an honours degree in the discipline of Computing will have achieved this. The modal standard is the average (taken over all years) of all the students 
graduating with an honours degree in the discipline of Computing. The following is the part of the standards section that addresses the concerns of this paper.

\section{Benchmarking standards}

Students should be able to

- at the Threshold level : identify appropriate practices within a professional and ethical framework and understand the need for continuing professional development;

- at the Modal level : apply appropriate practices within a professional and ethical framework and identify mechanisms for continuing professional development and life long learning;

The benchmarking criteria for each subject area have been undertaken by a group of subject specialists drawn from and acting on behalf of the subject community. The criteria are broadly based and cater for a wide variety of computing courses ranging from business-oriented information systems ones across the spectrum to hardware-oriented computing systems courses.

To sum up, UK universities has evolved a self-regulatory system through the QAA and its procedures where academic themselves can carry out periodic inspections (visits) to monitor that quality procedures are in-place and acted on and also to see that the benchmark standards are being met.

\section{BCS Accreditation}

\subsection{Criteria and Principles}

Departments in UK universities running degree courses that conform to the QAA Benchmark in Computing are invited by the Society to submit their courses for accreditation. Not wishing to stifle evolution and innovation, the Society is also willing to consider courses that may not entirely conform to the benchmark. The Society publishes Accreditation Guidelines (ref. 3) that contain the criteria that are expected to be met. The following gives the main sections of the Guidelines.

Criteria for Accreditation

2.1 Departmental Criteria

2.1.1 Quality Assurance

2.1.2 Learning Support

2.2 Course Criteria

2.2.1 Requirements for Honours Degrees

2.2.2 Requirements for courses other than Honours Degrees

2.3 Project Criteria 
Within the Course Criteria section an essential requirement for all courses is that they address Legal, Social, Ethical and Professional Issues (LSEPIs).

"The Society looks for course content which specifically aims to give students an understanding of the professional issues relevant to their future working lives, as well as a sound academic grounding in the discipline. A course should provide opportunities for a full appreciation of the wider issues of ethical standards, legislative compliance and the social and economic implications of information systems practice."

The expectation is that delivery and coverage of these issues are centered on the following principles: Breadth, Integration, Importance, Visibility, and Professional Behaviour.

\section{Breadth - non-technical requirements}

The course should give students an awareness of external factors which may affect the work of the computer professional:

- acceptance of responsibility for work which affects the public well-being

- professional behaviour

- statute laws which impact on the work of the information systems engineering professional

- computer safety and security

- principles of management and industrial relations.

\section{Integration}

Awareness of professional issues such as standards, codes of conduct and relevant legislation must not be separated from the practice of designing and implementing systems. It is essential that these topics are integrated into the course.

\section{Importance}

Students should not perceive legal, social, ethical and professional issues as peripheral to, or as less significant than, technical skills detailed in the syllabus. The Society considers that adequate coverage of legal, social, ethical and professional issues is important in the assessment and examination of accredited courses but accepts that the requirements may be met in many ways.

\section{Visibility}

The relevant legal, social, ethical and professional issues should be specifically detailed in the syllabus, mentioned in directions to students on practical assignments and work placements, and not left solely to the discretion of individual teachers. The central issues are important to all information systems engineering practitioners and must be addressed in core areas of the course rather than in options alone.

\section{Professional Behaviour}

In gaining exemption and accreditation, it is expected that all staff demonstrate and maintain high professional standards in their own use and practice of information systems engineering. Membership of a professional body would be one sign of such a commitment. The production and promulgation of codes of conduct for students, 
the displaying of notices relating to such things as copying software and virus protection are also signs of such a commitment.

\subsection{Location of LSEPI within degree programmes}

Undergraduate (honours) degree courses in the UK are typically of three years' duration (four years' in Scotland starting from a lower base). Rather than using 'years' courses are laid out in terms of three levels.

\subsubsection{Level 1}

The impetus in level 1 is to encourage students to act professionally as students and to introduce them to the idea of the need for professionalism in their future careers. Thus, the following topics are usually present in the first year of all computing courses.

\section{Laboratory safety}

Hacking and plagiarism

Learning skills

Investigations and presentations

Working to deadlines

Working co-operatively in teams

Areas of study can be combined effectively here. For example, students working in small groups can carry out simple investigations into LSEPI topics and report back with a presentation to the whole class.

\subsubsection{Level 2}

$80-90 \%$ of courses include a dedicated module on 'Professional Issues' that contains specific lectures, scenario investigations, group activity and presentations. Some students on more technically-based courses find lectures on the non-technical aspects difficult to follow. Consequently, the use of scenario-based investigations has proved particularly effective in introducing students to concepts beyond computer systems and programming.

\subsubsection{Level 3}

The final year of UK degrees have a compulsory project together with mainly optional modules or pathways. The principle at this level is that "Professional Issues should be included as and when relevant". Ideally, this implies an explicit statement in module specifications and appropriate assessment of the material. Many final year projects have scope for a consideration of ethical issues and the Society encourages reporting of these areas ion the student's final report.

\subsection{Issues surrounding the delivery of LSEPIs}

The following delineates some issues that Departments need to address when contemplating teaching LSEPI to a level acceptable for BCS accreditation. 
1. As stated in the QAA benchmark, what is an appropriate 'professional and ethical framework' for degree programmes?

2. What constitutes acting 'ethically/professionally' as a student?

-Plagiarism - positive contribution to group activities

3. What constitutes acting 'ethically/professionally' as lecturers?

-Professional response to students

4. What LSEPI content is it essential to include in every programme?

5. Should discriminatory issues be built into programmes, and if so how?

6. What learning experiences should we design for the students so that these areas of the curriculum are fully covered?

- Lectures

- Seminar work (presentations)

- Group activity through the use of scenarios

7. In what framework should the learning experience be set? Separate modules - fully integrated material - a mixture

8. How can all staff in a department be encouraged to take this area of the curriculum seriously?

9. In a research dominated environment how can department Heads be persuaded to take this area of the curriculum seriously?

To sum up, in an ideal situation, activity should take place within all three levels of an undergraduate degree programme. Computing departments should adopt an overall ethos, exemplified through explicit policy statements that encourage both staff and students to behave professionally. Policy should be reviewed on a regular basis and policy implementation should be subject to systematic monitoring.

\subsection{Review and Inspection Mechanisms}

The QAA review process is carried out by trained senior academics, not necessarily subject specialists, and focuses on the quality procedures of the University as a whole. The BCS accreditation is carried out by visiting panels of senior specialist academics augmented by industrialist with knowledge of academia. The focus of the $\mathrm{BCS}$ visit is on the departmental procedures that affect the quality of the student's learning experience and also the quality of the outcomes arising from that experience. A highlight of each visit is for the panel to meet with students taking each course and to verify their actual experiences. Panels visit every five years unless there are problems; then, more frequent visits are made. Minor defaults can be rectified by a departmental submission within 90 days of receiving the final report form the Society.

\section{Self-Regulation and Democracy}

\subsection{Democracy}

The ideal situation is where a department has made a positive response to all the issues listed in section 3.3. The Society has steadily worked towards this position 
since accreditation was first carried out more than thirty years ago. In the early days the newer universities were accustomed to CNAA reviews, but well-established universities found it more difficult to accept inspections. If a heavy-handed approach had been taken then many would have refused to take part in the process. However, with the support of several major institutions, we have arrived at a situation where every department in a UK University voluntarily seeks accreditation as a matter of course.

Actual accreditation is done through a visit to the University by a panel of assessors, one of whom is an industrialist. A feature of the panels is that they are composed of respected senior faculty members of both the established and the newer universities, together with an industrial assessor. The academic assessors are all senior members of other university computing departments who will undoubtedly be subject to an accreditation of their own department in turn. In this way a democratic process is created.

The assessment panels prepare reports that are brought to the Accreditation Committee of the Society before being sent to the relevant University. The Committee itself consists of a selection of the most senior and experienced of the assessors. Discussion of draft reports at this committee provides quality assurance for compatibility among the many panels needed to carry out the complete schedule of visits. Consequently, the approval mechanism is seen more as one of peer review rather than one of outside inspection, with constructive help and advice given as part of the process.

\subsection{Self-Regulation}

With respect to the QAA, this body was set up by academia in order to ward off any outside Government inspection regime. Subsequent governments have so far accepted this body as a sufficient watchdog to ensure the standards of university degrees. Thus, through self-regulation, universities have managed to escape from a very rigid regulatory structure.

While all universities have to take notice of the QAA, involvement of computing departments with the BCS is of a purely voluntary nature. Because of this appliance of strict regulations on accreditation visits would have been counterproductive with many universities not seeking approval. Getting agreement on the technical content of courses and their appropriate standards is to not too difficult a process. Also identifying the processes and resources needed for a quality learning environment is fairly straightforward. However, trying to introduce non-technical areas into traditional curricula, such the LSEPIs discussed previously, has taken longer. Where the Society has had to withhold accreditation this has been done in a constructive manner with, in nearly all cases, a positive outcome eventually resulting from the feedback provided.

\section{Conclusion}

The construction of assessment panels through the democratic process outlined in the previous section, and the taking of a supportive rather than a dictatorial role by the 
various panels, has meant that over a period of time the Society can justly point to the acceptance of its accreditation process in general and, in particular, to the introduction of a wide range of professional issues to all graduates from its accredited courses.

\section{References}

1. British Computer Society (BCS)

http://www.bcs.org/

2. BCS Code of Conduct

http://www.bcs.org/server.php?show=conWebDoc.1588

3. BCS Accreditation Guidelines

http://www.bcs.org/server.php?show=nav.7066

4. Qualification Assurance Agency (QAA)

http://www.qaa.ac.uk/aboutus/qaaIntro/intro.asp

5. QAA Subject Benchmarks

http://www.qaa.ac.uk/academicinfrastructure/benchmark/honours/default.asp 